YUNUS EMRE

VE DÜNYA DiLi

TÜRKÇE YILI

\title{
Yunus Emre Divanı'nda Kalp, Dil, Hatır/Hâtır, Gönül, Yürek ve Cân Sözcüklerinin Eşdizimlilikleri ${ }^{1}$
}

\author{
Bilal UYSAL ${ }^{2}$
}

Makale Türü: Araştırma Makalesi

\section{Öz}

Yunus Emre, günümüzde dahi rahatlıkla anlaşılabilen bir şairdir. O, arı duru Türkçesi ile Oğuz Türkçesinin teşekkülü safhasında önemli bir rol üstlenmiş ve bir medeniyet dilinin inşaasında adeta mihenk taşı rolü oynamıştır. Yunus Emre bir aşk, sevgi, muhabbet insanıdır. Çalışmada, Yunus Emre Divanı'nında bu duyguların insanda tecelli ettiği yerler olarak görülen kalp, dil (Far.), hatır/hâtır, gönül, yürek ve cân sözcüklerinin eşdizimlilikleri üzerinde durulmuştur. Eşdizimlilik (collocation) genellikle iki veya daha fazla sözcü̈̆̈̈n yaygın olarak aynı dizimde bulunması olarak tanımlanmaktadır. Eşdizimlilik yan yana kullanılan sözcükler olarak algılanmakla birlikte, zaman zaman araya başka sözcükler de girebilir veya sözcüklerin sıralaması da değişebilir. Bu çalışmada şiirde anlamsal bütünlük oluşturan birimlerde (beyit veya dörtlükler) anlamlı ve yaygın birliktelikler eşdizimlilik olarak ele alınmıştır. Sözcüklerin eşdizimli olabilmeleri için divanda en az $3 \mathrm{kez}$ eşdizimli olmalarına dikkat edilmiştir. Yunus Emre Divaninda kalp, dil (Far.) ve hatır/hâtır sözcüklerinin eşdizimlilik oluşturmadığı gönül, yürek ve cân sözcüklerinin ise eşdizimlilik oluşturduğu görülmüştür. Çalışmada ele alınan her sözcü̈̆̈̈̈n Yunus Emre Divani’nda ifade ettiği anlam, Güncel Türkçe Sözlük (GTS) ve Kubbealtı Lugatı'ndan (KB) alıntı ile açıklanmıştır, bu sözcüklerin edebiyatta nasıl karşıllk buldukları hakkında da bilgi verilmiş, bu sözcükle verilen mesaj üzerinde durulmuştur. Incelenen sözcüklerden elde edilen bulgular, bu sözcükler birbirlerine oldukça yakın anlam değeri taşımalarına rağmen, her birisinin farklı sözcüklerle eşdizimlilik oluşturdukları ve bu yapıların da oldukça farklı duygu değerlerine sahip oldukları görülmüştür. Bu nedenle yakın anlamlı olarak değerlendirebileceğimiz sözcüklerin farklı nüansları ifade ettikleri tespit edilmiştir.

Anahtar Kelimeler: Türkçe, Gönül, Yürek, Cân ve Eşdizimlilik

Atıf: Uysal, B. (2022). Yunus Emre Divanı'nda kalp, dil, hatır/hâtır, gönül, yürek ve cân sözcüklerinin eşdizimlilikleri. Anadolu Üniversitesi Sosyal Bilimler Dergisi, 22(Özel Sayı), 249-270.

\footnotetext{
${ }^{1}$ Bu çalışma etik kurul izin belgesi gerektirmemektedir.

${ }^{2}$ Afyon Kocatepe Üniversitesi Eğitim Fakültesi Türkçe ve Sosyal Bilgiler Eğitimi Bölümü, uysalbilal@hotmail.com, ORCID: 0000-0002-7198-8760
} 


\title{
Collocations of the Words Heart, Tongue, Sake/Remember, Heart, Heart and Soul in Yunus Emre's Divan
}

\author{
Bilal UYSAL ${ }^{3}$
}

Submitted by: 20.11 .2021

Accepted by: 01.01 .2022

Article Type: Research Article

\begin{abstract}
Yunus Emre is a poet who can be easily understood even today. He played an important role in the formation of pure and Oghuz Turkish and played a touchstone role in the construction of a civilization language. Yunus Emre is a person of love, attachment and affection. In the study, the collocations of the words heart, dil (Far.), sake/hatır, feeling, heart and soul, which are seen as the places where these feelings are manifested in people in Yunus Emre's Divan, are emphasized. Collocation is generally defined as the common occurrence of two or more words in the same syntax. Although collocations are generally perceived as words that are used side by side, from time to time other words can be inserted or the order of the words may change. In this study, meaningful and common associations in the units (couples or quatrains) that form semantic integrity in poetry are considered as collocations. In order for the words to be collocation, attention was paid to be collocation at least 3 times in the divan. In Yunus Emre's Divan, it has been seen that the words heart, dil (Far.) and sake / sake do not form collocations, while the words feeling, heart and soul form collocations. The meaning of each word discussed in the study in Yunus Emre's Divan is explained with quotations from Contemporary Turkish Dictionary (GTS) and Kubbealt Dictionary (KB), information is given about how these words correspond in literature, and the message given with this word is emphasized. Although the analyzed words have very close meaning values to each other, it has been observed that these words form collocations with different words and these structures have quite different emotional values in terms of discourse melody. For this reason, it has been determined that the words that we can evaluate as close meaning express different nuances.
\end{abstract}

Keywords: Turkish, Feeling, Heart, Soul and Collocation

\footnotetext{
${ }^{3}$ Afyon Kocatepe University, Faculty of Education, Department of Turkish Education, uysalbilal@hotmail.com, ORCID: 0000-0002-7198-8760
} 


\section{Giriş}

Yunus Emre, günümüz nesillerince rahatlıkla anlaşılabilen bir şairdir. O, oldukça yalın Türkçesiyle verdiği gönül açan mesajlarıyla Oğuz Türkçesinin teşekkülü safhasında oldukça önemli bir rol üstlenmiş, bir medeniyet dilinin inşaasında adeta mihenk taşı rolü oynamıştır. Nasıl ki Tanzimat Edebiyatının kurucuları için "Şinasi, Namık Kemal ve Ziya Paşa mektebi” deniliyorsa, Eski Anadolu Türkçesinin inşaasında oynadığ 1 rol ve kullandığı dil ve üslup ile sonraki nesilleri etkilemesi nedeniyle açtı̆̆ı yola "Yunus Emre mektebi" de denilebilir. Eski Türklerdeki alp tipi İslâmiyetle birlikte gaza anlayışıyla gazi tipine dönüşmüş, bu tip Anadolu'nun maddi fethini gerçekleştirmiştir. Anadolu'nun manevi fethini ise sufî de denilen ve Ahmet Yesevî anlayışıyla Horasan'dan Anadolu'ya gelen erenler gerçekleştirmiştir. Anadolu’nun Moğol işgaline uğradığı buhranlı dönemde erenlerin Anadolu'ya çaldıkları maya tutmuş, tekke ve zaviyeler yoluyla tasavvuf anlayışı yayılmış, onların gönüllere taht kuran mesajları ile de Anadolu'nun manevi fethi gerçekleşmiştir. Böylece Anadolu'nun fethi perçinlenmiştir. Yunus Emre bu manevi fethi yapan, en önemli şahsiyetlerden birisidir. O, Anadolu'ya Horasan'dan gelen ve Anadolu'yu tasavvuf kültürü ile mayalayan erenlerin yolunu takip etmiştir. Moğol bozgunundan sonra ortaya çıkan buhran döneminde verdiği mesajlar ile gönülleri fethetmesi bakımından da son derece önemlidir.

\section{Literatür Taraması / Yazın İncelemesi}

Yunus Emre bir aşk, sevgi, muhabbet insanıdır. Çalışma yalnızca Yunus Emre Divanı ile sınırlı tutulmuştur. $\mathrm{Bu}$ duyguların insanda tecelli ettiği yerler olarak görülen kalp, dil (Far.), hatır/hâtır, gönül, yürek ve cân sözcüklerinin divandaki eşdizimlilikleri üzerinde durulmuştur. Türkçede bu sözcükler yakın anlamlı olmalarına rağmen, her birisinin farklı dizgesel kullanımları ve gönderimleri vardır. Çalışmada sözcüklerin eşdizimli olabilmeleri için divanda en az 3 kez eşdizimli veya eşanlamlı yapı oluşturmasına dikkat edilmiş, günümüzde dahi günlük dilde yaygın kullanıma sahip eşdizimli yapılar, en az üç örnek kullanıma sahip değilse eşdizimli kabul edilmemiştir. Çalışmada sözcüklerin her birisi (kalp, dil (Far.), hatır/hâtır, gönül, yürek ve cân) müstakil başlıkta incelenmiş, sözcügün hangi sözcüklerle eşdizimlilik kurduğu tespit edilmiş, her birisi ayrı ayrı alt başlıklarda değerlendirilmiştir.

\section{Yöntem}

Araştırmada literatür taraması yapılmış, veri toplama yöntemi olarak da doküman analizi yapılmıştır. Araştırmadan elde edilen bulgular içerik analizi kullanılarak incelenmiştir. Eşdizimlilik (collocation) genellikle "İki ya da daha fazla sayıda birimin aynı dizimde bulunması" (İmer vd. 2011, s. 121; Vardar, 2002, s. 94-95) olarak tanımlanmaktadır. Buradan hareketle dilin temel taşı olan sözcüklerin yalnızca sözcük anlamlarıyla ele alınamayacağı, öbek yapılar ve eşdizimliliklerle dildeki ifadesini bulduğu anlaşılmaktadır. Eşdizimli sözcükler zamanla adeta mütümmim cüz gibi görülür, birisi söylenince hemen diğer(ler)ini çağrıştırır. "Belirli bir dizgede karakteristik ve sık olarak tekrarlanan sözcük birliktelikleri eşdizimsel anlamı oluşturmakta ve bir sözcügün anlam özellikleri ile kullanım özellikleri ancak o sözcüğün aynı dizgede yaygın olarak kullanıldığı diğer sözcükler aracılığıyla elde edilebilmektedir.” (Gündoğdu, 2019, s. 456).

Eşdizimli sözcükler mutlaka yeri değiştirilemez bir sıra ile ve yan yana olmak zorunda mıdır? Eşdizimlilik üzerine çalışanlar, bu konuya farklı yaklaşmaktadır. Eşdizimlilik genel olarak iki farklı bakış açısıyla ele alınmakta, bunlar istatistik temelli yaklaşım ve anlam temelli yaklaşım. "Bunlardan birincisi, belli bir dizimde belli bir aralıkta birlikte kullanımlar arasındaki sıklık dağılımının ortaya çıkarıldığı istatistik temelli yaklaşım (statistically oriented approach) ya da sıklık temelli yaklaşım (frequency-based approach); ikincisi ise, sözcük birlikteliklerinin tamamıyla değil de belli birtakım ölçütler dahilinde bir araya gelerek ortaya çıtığının düşünüldüğü anlam temelli yaklaşım (signifıcance oriented approach)'dır.” (Özkan, 2012, s. 97-98). İstatistik temelli yaklaşım, derlemden belirli ölçüte göre elde edilen ve yalnızca sabit olarak yan yana kullanılan 
sözcükleri eşdizimli kabul etmekte, anlam temelli yaklaşım ise bağlam içerisinde aynı anlamsal değere sahipse bu durumdaki sözcükleri de eşdizimli kabul etmektedir. "Eşdizimliliğin sadece yapısal yakınlıkların örüntülenmesi biçiminde karşımıza çıkmadığı, konunun bir diğer boyutunun, dizgede yer alan sözcüklerin anlamsal birliktelikleri olduğu, bu bağlamda birimlerin belirli bir nedenlilik ve açıklık çerçevesinde bu yapıyı oluşturduğu göz önünde bulundurulmalıdır.” (Eken, 2016, s. 43).

Eşdizimlilik genel olarak yan yana kullanılan sözcükler olarak algılanmakla birlikte, bazı çalışmalarda yan yana olmak şartı yerine aynı cümlede, paragrafta, beyitte veya dörtlükte birliktelik olarak ele alındığı da görülmektedir. "Diğer bir kavram 'anlamsal uyum'dur. Çalışmada, dizgesel yakınlıkların eşdizimsel yapıların kaynağını oluşturduğu bilinciyle, anlamsal uyumu göz ardı etmeyen bir yöntem benimsenmiştir. Bu anlamda tümce olarak da adlandırabilen ve kendi içinde dizisel bir bütün oluşturan söz dizgeleri ve bu dizgeler içerisinde var olan anlamsal uyumlar eşdizimlilik temelinde değerlendirmeye" (Özkan, 2012, s. 98) alınmalıdır. Bu çalışmada elde edilen veriler büyük bir çoğunlukla yan yana olmakla birlikte, eşdizimli sözcüklerin zaman zaman yan yana olmadıkları, ancak aynı anlamsal değeri taşıyan farklı sözcüklerin eşdizimlilik gösterdikleri yapılar da görülmüştür. Çalışma yalnızca Yunus Emre Divanı üzerinde yapılmış, bir şiir metni üzerinde yapıldığg için beyitlerde veya dörtlüklerde anlam bütünlüğü bulunduğu kabul edilmiştir. Yalnızca bir kişinin kaleminden çıkan şiirlerde eşdizimli sözcüklerin aralarına başka sözcükler girmesiyle anlam bütünlüğünün bozulmadığı, daha önce veya sonraki eşdizimli sözcüklerle aynı anlam değerine sahip oldukları görülmüştür. Yunus Emre'nin divanına bakılınca düşüncede belirli bir akış, birbiri ile ilişkili ve tutarlı bir söylemin olduğu görülebilir. Tabi ki eşanlamlı sözcüklerin tam olarak birbirinin yerini tutması mümkün değildir. "Türkçede eş anlamlı olduğu varsayılan, eş ve yakın anlamlılar (nearsynonym) sözlüklerinde yer verilen sözcüklerin pek çoğu aynı anlam alanına dâhil olmaları nedeniyle kısmî eş anlamlılık (partial synonymy) özelliği gösteren sözcüklerdir." (Sert, 2018, s. 96). Sabit ve yan yana olan eşdizimlilikler sıklık temelli, sabit olmayan ve aralarına başka sözcüklerin girmesiyle oluşmuş eşdizimlilikler ise anlam temelli eşdizimlilikler olarak görülmelidir.

Bu çalışma yalnızca Yunus Emre Divanı ile sınırlı tutulmuştur, ancak bu çalışmada incelenen eşdizimli sözcükler (kalp, dil (Far.), hatır/hâtır, gönül, yürek ve cân) yalnızca Yunus Emre’ye özgü değildir. Benzer eşdizimliliklere farklı eserlerde ve günlük kullanımlarda da rahatlıkla rastlamak mümkündür. "Söz konusu kullanımlar yalnızca bireysel dil kullanımlarını değil bütünsel bir dağılım ile dilin genel kullanımlarını kapsamaktadır. Bu özelliğe paralel olarak eşdizimliliklerin birçok durumda nedensizlik sergilediğini söylemek mümkündür."(Gündoğdu, 2019, s. 457).

Çalışmada bazı durumlarda eşdizimlilik oluşturan sözcüklerin anlam değeri değişmeden yer değiştirdiği de (gönül ve göz / göz ve gönül) görülmüsștür, örneğin aşağıdaki beyitlerde gönül ve göz sözcükleri yan yana olmakla birlikte dizimi oluşturan sözcüklerin yer değiştirdikleri, ancak yakın anlam değerine sahip oldukları görülmektedir:

Yûnus imdi sen Hakk'a ir dün ü gün gönlün Hakk'a vir

Gönül gözi görmeyince bu baş gözi görmeyiser

Eyâ gâfil aç gözüni gönlün yavlak uzatmagıl

Bakgll kendü dirligüne kimse 'aybın gözetmegil

Bazı durumda aynı beyitte olmakla birlikte araya başka sözcüklerin de girdiği görülmüştür, aşağıda cân vermek eşdizimliliklerinin arasına başka sözcükler girmiş, ancak diğer kullanımlarda görülen anlamın değişmediği görülmektedir: 
Cânını şükrâne vire yüzin ayaklara süre

Erenler gönline gire Hak'dan haber soran kişi

N'iderüz dirlik suyın biz cânı yagmaya virdük

Eşdizimli iki sözcük arasına başka ekler de girmiş olabilir, ancak aynı anlam değeri varsa bu tür yapılar da eşdizimli kabul edilmiştir:

Benüm gönlüm gözüm 'ışkdan toludur

Dilüm söyler yari yüzüm suludur

Çalışmada ele alınan her sözcük (kalp, dil (Far.), hatır/hâtır, gönül, yürek ve cân) önce Yunus Emre Divanı'nda kullanıldığı anlamı içeren açıklamalar, Güncel Türkçe Sözlük (GTS) ve Kubbealtı Lugatı’ndan (KB) alıntı ile açıklanmıştır. Daha sonra da bu sözcüklerin edebiyatta ve Yunus Emre Divanı’nda nasıl karşılık buldukları hakkında da bilgi verilmiş, bu sözcüklerle verilen mesaj üzerinde durulmuştur. Eşdizimli alt başlıklarda ise şayet ilgili yapıyla ilgili KB'de bir açıklama var ise onlar da verilmiştir.

\section{Bulgular ve Tartışma}

\section{Kalp}

Kalp, GTS'de “isim, mecaz Sevgi, gönül.” şeklinde, KL'de ise "Îman, sevgi ve nefretin, iyi ve kötü bütün duyguların, anlayış, duyuş, seziş yeteneklerinin kaynağı olduğu kabul edilen, insanın mânevî varlığının merkezi, gönül. s. Karnı açlardan ziyâde kalbi açlara acırım (Cenap Şahâbeddin). Kalp gözü, s. İnsanda bir şeyin gerçeğini ve anlamını sezen, anlayıp kavrayan güç, gönül gözü, basîret, s. Ey Şinâsî içimi havf-i ilâhî dağlar / Sûretim gerçi güler kalb gözüm kan ağlar (Şinâsî).” şeklinde tanımlanmıştır.

Vücuda kan pompalayan hayati bir organımız olan kalp, Arapça ters çevirmek, alt üst etmek anlamlarına gelir. Kalp bu anlamın ötesinde edebiyatta gönül anlamında kullanılmaktadır. Yunus Emre Divanı'nda bu yönüyle ele alınmıştır. Elde edilen verilere göre de kalp sözcüğü yerine daha çok gönül sözcüğünün tercih edildiği görülmüştür. Yunus Emre Divanı'nda kalp sözcüğünün yalnızca dört yerde geçtiği ve bunların da hiçbirisinin eşdizimli olmadığı görülmüştür. Bu dört beyit aşağıda gösterilmiştir:

1

Yoldan haber sorarlar eydürem inanurlar

Kalbüm sâfî sanurlar vay ne düşvâr iş benüm

2

Gel beri kulum diyüp kalbüne nazar salup

Câm-ı ebedî sunup hayrân olasin birgün

3

Her kime kim dervîşlik bagışlana

Kalbı gide pâk ola gümüşlene

4

Mine'l-kalbi ile'l-kalb yol var dimişler erler

Her gönülden gönüle rast togru yol degül mi

Dil

Dil, GTS'de “dil (III) isim, Farsça dil, s. Gönül, yürek.” şeklinde KL'de ise "(Eski Türk. tıl > til > dil) (Fars. dil) Gönül, yürek, s. Oldum garîk-i bahr-ı hatâ ey dil el-aman (Fıtnat Hanım)” şeklinde tanımlanmıştır. 
Aşağıda da görüldüğü üzere Farsça gönül anlamına gelen dil sözcüğü, bu anlamıyla yalnızca 3 yerde geçmiş, bu kullanımlarda da herhangi bir eşdizimlilik tespit edilmemiştir. Bu da bize Yunus Emre'nin şiirlerinde Türkçe gönül sözcüğü yerine Farsça dil sözcüğünü tercih etmediğini göstermektedir. Gezginci bir derviş olarak geniş halk kitlelerinin arı duru Türkçesini bu kitlenin rahatlıkla anlayabileceği şekilde şiirine taşıdığı görülmektedir. Türkçe gönül yerine yalnızca üç yerde Farsça dil sözcügünü kullanmış, bunun nedeni ise şiirde ölçüyü tutturmak için ve cümlenin akışına göre yaygın bir kullanımı olduğu için tercih ettiği görülmektedir.

\section{5}

Dildâr içün dil şehrini pâk eyle arıt gayrıdan

Zîrâ ki sultân tahtıdur bunda komazlar zâgları

6

Kanca vardun iy 'âkil bir agızdan cümle dil

Cüz'iyyât-1 müselsel haber virür 'akl-1 kül

7

Eyyûb'am dil mübtelâyam derde dermân isterem

\section{Hatır / Hâtır}

Hatır, GTS'de “İsim Gönül, kalp, s. Sakın hatırını kıracak bir şey söyleme.” şeklinde KL'de ise "Hatır - Hâtır (خاطر) i. (Ar. huțūur 'akla gelmek' ve hāț̣ir 'kalp’ten huāṭir) Gönül, duygu, his, s. Hatıra dokunup yıkıcı olma (Karacaoğlan)" şeklinde açıklanmıştır.

Aşağıda görüldüğü üzere Yunus Emre divanında hâtır sözcüğü gönül anlamında iki beyitte üç kez geçmiş, ancak bunlardan yalnızca iki tanesi hatır sormak şeklinde eşdizimlilik oluşturmuşsa da en az üç örnek olması gerektiği için eşdizimli olarak alınmamıştır. Bir sözcüğ̈̈n Türkçesi var ise Yunus Emre onu tercih etmektedir. Burada halkın dilinde yaygın olarak kullanılan ve bir kimseyle yakından ilgilenmek, hâlini hatrını sormak anlamlarına gelen hatır sormak sözcüğünü tercih etmiştir. Bu yapı ifade ettiği anlam ezgisi ile yaygın bir eşdizimlilik oluşturduğu için tercih etmiştir, ancak bu anlam ezgisinin, gönderimin dışındaki yerlerde daha çok gönül sözcügünü tercih ettiği görülmektedir.

8

Görmege gelenleri hâtırun soranları

Sevgili yârânları görmez olasın birgün

9

Ben garîbün hâtırını sormaga geldi şol sanem

Düzdi gönül sınugını hâtır ziyâret eyledi

\section{Gönül}

Gönül, GTS'de “İsim Sevgi, istek, düşünüş, anma, hatır vb. kalpte oluşan duyguların kaynağ1, s. 'Gönüllerin birbirine kaynaştı̆̆ı o günler millî bayramlarımızdan biriydi.' - Orhan Seyfi Orhon” şeklinde KL'de ise “Îman, sevgi ve nefretin, iyi ve kötü bütün duyguların kaynăğ olduğu kabul edilen kalbin mânevî yönü, yürek, dil, s. Estikçe bâd-ı subh perîşansın ey gönül / Benzer ki esîr-i turra-ı cânansın ey gönül (Nedim'den)" şeklinde açıklanmıştır.

Gönül sözcüğü kalbin manevi yönünü temsil eder. Bu anlamı yakın gönderim ile kalp sözcügü de ifade etse bile gönül sözcügünün baskın bir şekilde tercih edildiği görülmektedir. "Farsça dil, derûn; Arapça kalb, hâtır; Türkçe yürek kelimeleriyle de karşılanan gönül Türk edebiyatının divan, halk ve dinî-tasavvufî mahsullerinin en önemli ve en çok işlenen konularından biridir... İmanın ve küfrün merkezi kalptir. Kalp iman nuru ile 
dolduğunda gönül, inkâra ve küfre yöneldiğinde ise nefistir. Gönül ulviyete, nefis süfliyete yönelir. Mâna âlemini kuşatan gönül, Hak yolcusunun varacağı son merhaledir.” (Kurnaz, 1998, s. 151). Tasavvufta gönül, insan kalbinin rahmânî yönünü temsil eder, süflî yönünü ise nefis temsil eder. Tasavvufta gönül sözcüğü değişik sözcüklerle birlikte kullanılır, ancak daima olumlu anlamda kullanılır. "Türk tasavvuf edebiyatında kalp ve dil terimlerinin yanında Türkçe gönül kelimesi de kullanılmış, bazı tasavvufî kavramlar bu terimle ifade edilmiştir. Genellikle gönül 'tasavvuf, gönül ehli de 'sûfiler' anlamına gelir. Gönül haline varmak râbıta ve murakabe halinde olmak demektir.” (Kurnaz, 1998, s. 152).

Çakıroğlu, Gönül Çalabun tahtı gönüle Çalab baktı / İki cihan bed-bahtı kim gönül yıkarısa beyitinden hareketle Yunus'ta gönül sözcüğünün değişik anlamları olduğunu belirtir. Bunlardan birisi “Cenab-1 Hakk'ın insanda tecelli ettiği yer, tasavvufi aşkın kaynağı kısacası aşkın tecelli ettiği yerdir”. (2013, s. 2). Yunus, insan gönlünü Allah'ın tahtı olarak görür; gönül, insanın Allah ile buluştuğu yer olarak görüldüğü için aynı zamanda Ka'be'dir. Bu nedenle gönül kıran gerçekte Allah'ı incitmiştir. İşte bu yüzden kim gönül yıkarsa o kimse her iki dünyada da bedbahttır. Yunus Emre de gönül yapmayı hacca gitmekten daha üstün görmüştür.

Mademki gönül, insanda Allah’ın tahtıdır, insan gönlünde mâsivânın (Allah’tan başka her şey) yeri yoktur.

Sekiz uçmağun hûrisi eger bezenüp geleler

Senün sevgünden özgeyi gönlüm hiç kabûl itmeye.

Yunus Emre, gönül tahtının sultanı olarak Allah’ı görür, ancak Peygamber Efendimiz (SAV) de gönlümüzde yer eylemiştir, bu nedenle ona ümmet olan, onun yolundan giden cehenneme girmez.

\section{Gönüllerde yir eylemek Muhammed'e gelmişdurur}

Mustafầya ümmet olan tamuda karâr eylemez

Aşağıda söylendiği gibi akıl ve gönlün her ikisi de insanda bulunmalı, bu durumda düşman zarar veremez. Yunus Emre şiirlerinde yeri geldikçe aklı üstün tutmuştur, ancak $\mathrm{O}$, akıl şairi olduğu kadar aynı zamanda gönül şairidir.

Eger 'akıl başdayısa gönülde ol tuşdayısa

İkisi bir işdeyise düşman bana kâr eylemez

Kabe maddi manada Allah'ın evidir (beytullah), Müslümanların kıblesidir, manevi olarak ise insan gönlü Allah'ın evidir. Alemlere sığmayan Allah, insan gönlüne sığmıştır. "Kabe, maddi ve dışa ait bir mekân buna karşılık gönül ise manevi ve 'iç'e, öze ait bir mekândır. Bununla birlikte Kabe'de şekle dayalı uygulamalar ve ritüeller söz konusu iken gönülde içsel bir yolculuk söz konusudur. Yunus burada Kabe ve gönlü kıyaslar ve Allah'ın kullarının gönlünü mesken tutması gerçeğinden hareketle gönlü daha 'yeğ’ kabul eder. Gönül mi yig Ka’be mi yig eyit bana 'aklı iren / Gönül yigdür zira ki Hak gönülde tutar turakı ( 366 / 7 )” (Akbalık, 2013, s. 23).

Yunus Emre Divanı'nda Gönül sözcügünnün 277 yerde geçtiği tespit edilmiştir. Ancak bu çalışma gönül sözcüğünün yalnızca eşdizimlilik oluşturduğu beyit ya da dörtlüklerle sınırlandırılmıştır. "Yunus Emre’nin şiirlerinde 'gönül' farklı telakkilerle karşımıza çıkmaktadır. Allah'ın ve aşkın tecelli ettiği bir mekân olarak gönül en çok Hak ve aşkla birlikte anılmaktadır.” (Tatçı, 1990, s. 237). Divan'da gönül sözcüğünün eşdizimlilik kurduğu yapılar şunlardır: 


\section{Gönül / göz (gönül gözü)}

KL'de gönül gözü "Mânevî temizliğin ve olgunluğun insana verdiği uyanıklık, gördüğü şeyin gerçeğine varma hassası, kalp gözü, sağ görü, basîret, s. Uyan gafletten aç gönül gözünü / Cenâbından yana dönder yüzünü (Aziz Mahmud Hüdâyî).” şeklinde açıllanmıştır.

Yunus Emre gezginci bir derviştir. Onun şiirlerinde tasavvufî bir esinti bulmak mümkündür. Gönül gözü de onun en fazla kullandığı tasavvufi kavramlardan birisidir. Olgun müminlerde bulunan önsezi yeteneğidir. Nefsin eğitilmesi ile belirli basamakları aşmasının bir sonucu olarak, insanın hayata sırf akılla bakmak yerine sezgilerle de bakabilme yetisidir. Dünyaya maddi gözlerle bakmaktan ziyade mânâ yönüyle de bakabilmektir. $\mathrm{Bu}$ da gönül gözü ile bakabilmekle mümkündür. Bu yüzden İnsanın maddi gözüne basar, kalp/gönül gözüne de basiret denilmiştir. Gönül gözü ile görmek duyu organı ile maddi olarak görmekten öte ruhun incelmesi ve eğitilmesi ile ortaya çıkan bir melekedir. İnsan beden gözü ile dünyayı görür, aklıyla kavrar, ancak o gerçekliğin arkasında görünmeyeni gönül/kalp gözü ile görür. Gönül ehli insanların "Kalpten kalbe bir yol vardır görülmez” dedikleri de işte budur. Bazı hâller maddi gözle görülmez, ancak gönül gözü ile görülür. "Mutasavvıflar, insanın dış âlemi gören bedendeki iki gözüne karşlık kalbin de iç âlemi gören iki gözü bulunduğunu kabul eder ve buna aynü'l-kalb, dîde-i cân, çeşm-i bâtın-bîn, mârifet gözü ve kalp gözü gibi isimler verirler. Bedendeki göz maddî âlemdeki varlıkları, olayları, renkleri ve şekilleri gördüğü gibi gönül gözü de dış âlemdeki eşya ve olayların iç yüzünü ve mânevî âlemdeki hakikatleri görür. Bedendeki göz insanlarla hayvanlar arasında müşterektir, fakat kalp gözü insanlara mahsustur. Basîret gözü her insanda kuvve halinde vardır. Bazı kimselerde bu göz Allah vergisi (vehbî) olarak doğuştan açık olursa da çok defa his perdesiyle örtülü olduğundan onu mücahede ile açmak gerekir." (Uludağ, 1992, s. 103).

Yunus Emre divanında gönül ve göz sözcükleri 12 yerde eşdizimlilik oluşturmuştur. Burada her iki sözcük genellikle yan yana olmakla birlikte beyit içerisinde farklı yerlerde oldukları da görülmüştür. Yalnızca bir yerde (19. örnek) gönül gözü yerine eşanlamlı ve eşgönderimli cân gözü kullanılmış, ayrıca aynı beyitte gönül sözcüğü de geçmektedir.

10

Yûnus imdi sen Hakk'a ir dün ü gün gönlün Hakk'a vir

Gönül gözi görmeyince bu baş gözi görmeyiser

11

Dünyâ gözün rûşen idüp gönül gözün kör eyledün

Zulmet tolıcak gönlüne 'ş̧k n'eylesün senünile

12

Gönül gözi bîdâr durur her kanda baksam yâr durur

Kimde 'akıl-fehim vardur ol bilür benüm sözümi

13

Üçüncisi ma'rifet cân gönül gözin açar

Bak ma'nî sarâyına 'Arş'a degin yücesi

14

Ta'n idersin 'âşıklara gönül gözi açıklara

Uymışsın münâfiklara sıdka gelmeyesin bigi

15

Benüm gönlüm gözüm 'ş̧kdan toludur

Dilüm söyler yari yüzüm suludur

16

Şükür Hakk'a kim dost bize eyitdi dost yüzine bak 
Açdum ben de gönlüm gözin sultânumı gördüm mutlak

17

N'itsün bu Yûnus n'itsün bu yola niçe gitsün

Gönlini sana virüp gözlerin humâr itsün

18

İçün taşun murdâr iken 'ışk n'eylesün senünile

Gönlün gözi uyur iken 'şsk n'eylesün senünile

19

Cân gözi ant gördi dil andan haber virdi

Cân içinde oturdı gönlümi 'Arş eyledi

20

Ol dost açdı gözümi gösterdi kendözümi

Gönlümdeki râzumı söyledüm dile geldüm

21

Benüm gönlüm gözüm 'aşkdan doludur

22

Eyâ gâfil aç gözini gönlün yavlak uzatmagıl

\section{Gönül şehir / ev (Gönül şehri/evi)}

Gönül evi KB'de "Dil hânesi, s. Gönül evi, gönül, s. Gözden nihân olsa hüsn ü cemâlin / Muhabbetin çıkmaz dil hânesinden (Erzurumlu Emrah)." şeklinde tanımlanmıştır.

Kalbin maddi ve manevi olmak üzere iki yönü vardır. Maddi olarak vücudumuza kan pompalayan en önemli organımızdır, bu yönü işaret etmek üzere yürek de kullanılır. Kalbin bir de şuur, idrak, vicdan gibi irfani olgunluğu ifade eden rabbani melekeleri vardır ki bu da kalbin manevi yönüdür, buna da gönül denir. İnsan gönlüne beytullah (Allahın evi) da denilmiştir. İnsan hem âlem-i sugradır (küçük bir kâinat) hem de gönlü sayesinde âlemleri içine alan nüsha-i kübradır (kâinat). Gönül iyi veya kötü bütün duyguların merkezidir, bu nedenle eğitilmeli, arındırılmalıdır.

Bazı beyitlerde gönül ile ev birlikte geçer. Çünkü marifetin tecelli edeceği yer gönül evi/şehridir. Yunus’a göre Allah, gönül evini/şehrini "insanın bedeni ve ruhu arasında, maddî ve manevî dünyanın birleştiği yerde, şehir sembolüyle ifadelendirilen kalbi, gönül şehrini yaratmıştır.” (Okudan, 2012, s. 269). Yunus Emre divanında Türkçe gönül sözcüğüne karşlık gelen Farça dil sözcüğü ve yine yakın anlamlı cân sözcüğü ile toplam 6 yerde yakın anlamlı eşdizimliliğe rastlanmıştır. Bu kullanımlarda dikkat çekici olan taraf, bu farklı sözcüklerle yakın anlamlı gönderim yapılmış olmasıdır. Bu nedenle aşağıdaki beyitlerde gönül şehri, gönül evi, dil şehri ve cân evi eşanlamlı eşdizimlilik oluşturmuşlardır.

23

Ma'rifet gönül şehri makâmun bulur fakrı

Bahrî gerekdür bahrî bu ma'rifet içinde

24

Girdüm gönül şehrine taldum anun bahrine

'Işkıla seyr iderken iz buldum cân içinde

Yunus Emre gönül sözcüğünü $e v$ sözcügü ile de kullanmış, böylece gönlü Allah’ın evi olarak nitelendirmiştir. “Tanrının insandaki yegâne tecelligâhı olarak anlam ve kutsiyet kazanmıştır.” (Akbalık, 2013, s. 28). 
25

Zinhâr gönül evinde tutma yavuz endîşe

Biregüyçün kuyı kazan 'âkıbet kendü düşe

26

Evvel kapu şerî‘ at geçse andan tarîkat

Gönül evi ma'rifet 'ş̧k hakîkat içinde

Aşağıda ise gönül şehri/ evi yerine eşanlamlı cân şehri ve Türkçe gönül sözcügünün Farsça karşıllğı olan dil sözcügü ile dil şehri eşdizimlilikleri görülmektedir. Bu örnekler de yakın anlamlı gönderim yapılarak oluşturulmuş ezdizimliliklerdir.

27

Dostdan yana giden kişi kendözinden geçmek gerek

Dost yagmâlar cân şehrini alur gönül kal'asını

28

Dildâr içün dil şehrini pâk eyle arıt gayrıdan

Zîrâ ki sultân tahtıdur bunda komazlar zâgları

\section{Yürek}

Yürek, GTS'de "İsim, mecaz Herhangi bir şeyden çekinmeme, korkmama, yüreklilik, korkusuzluk, cesaret, s. Bu iş yürek ister." şeklinde KL'de ise "İnsanın bütün duygularının kaynağı ve mânevî varlığının merkezi, gönül, s. Çehre yüreğin aynasıdır derler (Ahmed Midhat Efendi). İn de a'mâkına bir bak ne derinmiş o yürek / Dalgalandıkça içinden taşan îman denizi (Mehmet Âkiften). Hayat, aşk, iyilik, cesâret / Ne varsa bu yürektedir (Câhit S. Tarancı)" şeklinde açıklanmıştır.

Arapça kalp ile eşanlamlı olan Türkçe yürek rahmani duyguların hâkim olduğu bir yer olarak görülmektedir. Yürek sözcügü gönümüzde de vicdanın sesidir, yüreğinin sesini dinlemek vicdanlı olmak demektir. Aşk, yürekte bir ateştir, bu nedenle yürek yarası aşka giriftar olunduğunu gösterir. Yunus Emre Divanı'nda yürek sözcügü $o k$, od, aşık/'ışk sözcükleri ile eşdizimlilik oluşturmuştur.

\section{Yürek / aşk}

Aşkın yürekte bulunduğu düşünülür, bu nedenle yürek ile aşk da eşdizimli sözcüklerdir. Ayrıca Yunus Emre bazı beyitlerde aşk sözcügünün yerine daha önce geçtiği için atıfta bulunmak üzere zamir de kullanmıştır, örneğin aşağıda aşk yerine bu yol sözcüğünün kullanıldığı görülmektedir. Bu eşdizimliliğe yalnızca dört yerde rastlanmıştır. Burada dikkat çekici hususlardan birisi de ikili eşdizimliliklerde nadiren görülen araya sözcük girme durumunun yürek ve aşk eşdizimli örneklerinin tamamında görülmüş olmasıdır. Yürek sözcügünün temel anlamı insan vücuduna kan pompalayan organ, kalptir. Edebiyatta ise soyut bir kavram olan aşkın mekânı olarak görülmektedir, bu noktada gönül sözcüğü ile yakın gönderimde bulunmakta, ancak gönül sözcügünün gönderim alanı dışında farklı anlamları karşıladığı görülmektedir. Her ikisi de Türkçede eski zamanlardan bu yana kullanılan bu sözcüklerin farklı gönderimleri ve ezgilerinin olduğu, bu nedenle de birbirlerinin yerlerine kullanılamadıkları görülmektedir.

\section{9}

Nazarun bin cân alur derdün yürekde kalur

Gören kendüden varur 'âşılka kıyan mısın

30

Anun 'ışk ş̧arâbın nûşidelden 


\author{
İrişür yüregüme yâre karşu \\ 31 \\ Benzüm sarı gözlerüm yaş \\ Bagrum pâre yüregüm baş \\ Hâlüm bilen dertlü kardaş \\ Gel gör beni 'işs n'eyledi \\ 32 \\ Bu yola yarak gerek eksük gerek çok gerek \\ Key demür yürek gerek bu sarp yola giresi
}

\title{
Yürek / 'ışk odu
}

Yürek ile 'ş̧k/aşk odu (aşk ateşi) arasında 6 yerde eşdizimlilik görülmüştür. Burada "aşk odu"nun yüreği yaraladığı görülmektedir. Aşk odu yani aşk ateşi yandığı müddetçe aşk devam eder, bu nedenle her ne kadar yüreği yaksa da aslında aşk ateşinin sönmesi istenmez. Bütün sermaye aşkın ateşinin için için tütmesindedir. Son beyitte ise aşk yerine eşanlamlı muhabbet sözcüğü ile eşgönderimli eşdizimlilik oluşturmuştur.

Aşağıdaki 6 örneğin dördünde yürek ile aşk odu arasına başka sözcükler girmiştir, bu da bize ikili eşdizimliliklerde nadir olarak görülen araya başka sözcük girme durumunun üçlü eşdizimliliklerde yaygın olduğunu göstermektedir.

33

İy dost senün 'ışkun odı cigerüm pâre baş kılur

'Işkundan yanar yüregüm yandugum bana hoş gelür

34

'Işkun odı yüregümde neler eyler neler eyler

Bugün bir 'âşı kı gördüm bu derdümden haber söyler

35

'Işkun odı yüregümde yandugına 'âlem tanuk

Kanda bir od yanarısa nişânı var dütün tüter

36

'Işkun odı düşdi câna eritdi yürek yagını

Kesdi hevâsetün kökin oda yandurdı bâgını

37

Yine yüzini gördüm yine yüregüm yand

Dost senün 'ş̧kun odı yüregüme dayandı

38

Bu mahabbet odı benüm yüregümde yana durur

Denize gark olurısam söynüp hatâ kılmaz benüm

\section{Yürek / 'ışk oku}

Yürek ile 'işk/aşk oku arasında 3 beyitte eşdizimlilik görülmüştür. Burada aşk okunun yüreği yaraladığı görülmektedir. Ancak bu yaralanma kötü bir durum olarak görülmemekte, insanı bir derde giriftar eyleyen, onun için her türlü çileyi çekmeyi göze aldıran, ilk hareketi sağlayan (müteharrik) bir durum olarak görülmüştür. Bu üç sözcükten yürek ile aşk oku arasına üç beyitten ikisinde başka sözcükler girmiştir, bu da bize tıpkı yukarıda "yürek / aşk odu" örneğinde olduğu gibi ikili eşdizimliliklerde nadir olarak görülen araya başka sözcük girme durumunun üçlü eşdizimliliklerde ise yaygın olduğunu göstermesi bakımından dikkat çekicidir. 


\section{9}

İy Yûnus sen dostunun cefâsina katlangıl

Yüregine 'sşk okın urmayan 'âşık mıdur

40

'Işkun okı demreni dokınur yüregüme

'Işk içün ben öleyin demren kayusı degül

41

Şöyle delü olmışam bilmezin dünden güni

Yüregümde işledi 'sşk okınun yaresi

\section{Yürek / yanmak (yüreği yanmak)}

Yüreği yanmak KL'de "Yüreği yanmak, s. Felâkete uğrayıp büyük bir acı duymak, s. Cayır cayır yüreğim yanıyor (Hüseyin R. Gürpınar)" şeklinde açıklanmıştır.

Yürek ile yanmak arasında da 6 yerde eşdizimlilik görülmüştür. Yüreğin yanması da tıpkı aşk okı ile yaralanması gibi olumsuz bir durum değildir. Aşk ehlinin olgunlaşması için manevi olarak yanması gerekmektedir. Çünkü aşka giriftar olanın yüreği yanar, "Işkundan yanar yüregüm yandugum bana hoş gelür” yandıkça muhabbet artar. Aşağıdaki ilk beş beyitte yüreği yanmak, aşk ateşiyle yanmak anlamındadır, 6. beyitte ise yüreği yanmanın sebebi aşk değil ölümdür. Yürek ve yanmak eşdizimliliklerinde dikkat çeken husus, 6 örneğin 1 tanesinde gönderimin farklı olmasıdır. İlk 5 örnek aşkın ateşine gönderim yapmaktayken, 6 . örnekte ölümün verdiği acıya gönderim yapılmaktadır.

\section{2}

Yandı yüregüm dutuşdı bagrum cigerüm kebâb durur

'Âşılarun şerbetleri bu derdüme sebeb durur

43

'Işkuna düşenlerün yüregi yanar olur

Kendüyi sana viren dükeli işden geçer

44

Bu mahabbet odı benüm yüregümde yana durur

Denize gark olurısam söynüp hatâ kılmaz benüm

45

İy dost senün 'ışkun odı cigerüm pâre baş kılur

'Işkundan yanar yüregüm yandugum bana hoşgelür

46

'Işkun odı yüregümde yandugına 'âlem tanuk

Kanda bir od yanarısa nişânı var dütün tüter

47

Alur yigidün hâsını döker gözlerin yaşını

Mecnûn ider anasını yüreklerin yakar ölüm

Cân

Cân, GTS’de "İsim Gönül, s. 'Çirkin bana kurban, ben de güzele / Can sever güzeli, maldan ziyade' - Karacaoğlan” şeklinde KL'de ise "İnsanın duygularını taşıyan iç âlemi, gönül, iç, yürek, s. Ol beni cân ile seven ümmetim (Süleyman Çelebi). Bilmek istersen seni / Cân içre ara cânı / Geç cânından bul anı / Sen seni bil sen seni (Hacı Bayram Velî̀den). Kadın kadıncığa benziyorlar. İkisini de canım sevdi (Hüseyin R. Gürpınar). şeklinde açıklanmıştır. 
Sözlüklerde de görüldüğü üzere cân sözcügünün çok değişik anlamları vardır. Edebiyatta daha çok manevi değeri yüksek arzulara kavuşmak için cân feda edilmesidir. "Sözlükte 'rüzgâr, nefis, ruh, bedenin hayatiyetini sağlayan ana unsur' mânalarına gelmekte ve Türkçe'de daha çok son iki anlamda kullanılmaktadır... Divan edebiyatının hayal ve remiz dünyasında can, genel olarak varlı̆ğ bilinen fakat gözle görülüp elle tutulamayan bir özelliktedir." (Uzun, 1993, s. 138). Cân elle tutulamadığı için uçucu kabul edilmiş, bu yönüyle kuşlara benzetildiği de olmuştur. Cân sözcüğünün sevgili yerine de kullanıldığı görülmektedir. "Zaten can sevgiliye aittir. Fuzûlî̀nin, Cânı cânân dilemiş vermemek olmaz ey dil / Ne nizâ eyleyelim ol ne senindir ne benim beyti bunu anlatır. Can bazan sevgili yerine kullanıldığından şiirlerde 'ey can' veya 'cânâ' hitabına sık sık rastlandığ 1 gibi sevgilinin bir diğer adı olan 'cânân/cânâne' de çok zikredilir... Cânânsız can, cansız ten gibidir.” (Uzun, 1993, s. 138). Tasavvuf şiirinde çok geniş bir kullanım alanı olan bu sözcük "bazan Allah anlamında, bazan Resûlullah, bazan da şeyh için” (Uzun, 1993, s. 139). kullanıldığı da görülmektedir. Cân ile eşdizimlilik oluşturan sözcükler şunlardır:

\section{Cân / almak}

KL'de cân almak "Öldürmek, s. Kirpiklerin hançer can alır gözün / Yüreğime koydum ateşin közün (Karacaoğlan).” şeklinde açıklanmıştır. Cân ve almak sözcükleri hayatla, canlılıkla ilgilidir. İnsana cânı/hayatı veren Allah'tır, alacak olan da Allah'tır. İnsan fâni, Allah ise bakidir, bu nedenle fani olan cân sahibi bilir ki kendisine bu cânı bahşeden bir gün alacaktır. Bu nedenle cân ile almak sözcükleri eşdizimlilik oluşturmaktadır. Yunus Emre divanında 6 yerde cân ve almak sözcükleri eşdizimlilik oluşturmuştur. Bunların tamamında cân Allah uğruna, yalnızca onun rızası için verilmiştir. İlahi aşka giriftâr olan, cânını onun uğruna seve seve vermesidir. Aslında cân terkedilirken cânâna vuslat söz konusudur. Bu nedenle cân seve seve verilmektedir.

48

Nazarun bin cân alur derdün yürekde kalur

Gören kendüden varur 'âşıka kıyan misın

49

Cân ne imiş dost yolına 'âşık anı terkitmeye

Bu cânıla bin cân alur cânın Hak'a viren kişi

50

Cân hulkuma geldükde 'Azrâîl'i gördükde

Yâ cânumı aldukda âsân ola mı yâ Rab

51

Öldügüm içün gussa mı yirem

Ala cânumi yine yaradan

52

Yûnus kim öldürür seni viren alur yine cânı

Yarın göresin sen anı er nazarından gitmegil

53

Alaldan cânumı 'ş̧k-ı İlâh ı̂

Benem Mecnûn gibi âvâre karşu

\section{Cân / fedâ kılmak / fedâ olsun / kurban kılmak / cânundan geçmek}

KL'de cân fedâ (kurban) 'Çok beğenilen şeyler karşısında söylenir, s. 'Dostluğun böylesine can fedâ.' 'Böyle hocaya can kurban.' Yanındaki için ne dersiniz? -Bak ona can kurban (Yâkup K. Karaosmanoğlu'ndan)” şeklinde açıklanmıştır. Her kim âşık ise aşkı uğruna cânını feda etmelidir. Burada asıl eşdizimlilik oluşturan sözcükler cân feda kılmak iken aynı anlama gelen cân feda olsun, cân kurban olsun ve cânundan geçmek 
sözcükleri de eşanlamlı olarak kullanılmıştır. Bunların hepsi de eşgönderimde bulunmaktadır. Yunus Emre Divanı’nda bu dört farklı dizimde dokuz eşdizimlilik tespit edilmiştir. "Gerçek aşk ve âşık candan geçebilmekle ölçülür. Fuzûlînin, Âşıı oldur kim kılar cânın fedâ cânânına / Meyl-i cânân etmesin her kim ki kıymaz cânına beyti bu düşüncenin âdeta darbımesel haline gelmiş bir ifadesidir.” (Uzun, 1993, s. 138). Yunus Emre de Sen cânundan geçmeden cânân arzû kılursın diyerek ilahi aşka, cânâna vasıl olmak için cân fedâ etmek gerektiğini belirtmektedir. Aşağıdaki beyitlerde şair, bu çileli yoldan (aşk) ve yolculuktan büyük bir hoşnutluk içinde, bu nedenle buldum ballar balını kovanım yağma olsun misali cânını feda eylemektedir. Bu yolda seve seve cân vermek söz konusudur. Hatta cân vermenin az bile olacağı düşüncesi hâkimdir. "O, ne güzel Mevlâdır ne eşi bulunmaz yardımcıdır." (Enfal 40). Kur’an-1 Kerim’de de ifade edildiği üzere Yunus Emre de "Uğruna cân feda edilecek yâr/dost var mıdır?" diye sorar ve cânın ancak Allah için feda edileceğini belirtir. Aşağıda yalnızca dörtlükte Allah dışında bir varlığa cân feda edilmekte, onlar da Allah dostu dervişler oldukları için.

54

Zamân bî̀-vefâları cefâ kılur Yûnus'a

Bir togru yâr bulıcak fidî kılur cânını

55

İşde bir yâr bulasın cânun fidî kılasın

İnkârıla gelenler erün yoldaşı degül

56

'Aceb degül senün içün ger cân fidî kilurısam

Senün varlıgun cân yiter hoşdur cânsuz kalurısam

57

Ben sevdügüm ma'ş̂ेkayı sen dahı bir görseyidün

Virmeyedün bu ögüdi fidâ kılaydun sen cânı

58

Râzîyam ol oda ben günde bin kez yanarısam

Gör niçe cân fidâ kilur şem‘i öninde pervâne

59

Yûnus kulun ögürsüz

Kimsesi yok yalunuz

Fidî olsun cânumuz

Eve dervîşler geldi

60

İy Tanri'yı bir bilenler cân Hakk'a kurbân kılanlar

Ölü degüldür bu cânlar ‘şsk gölinde yüze durur

61

Sen cânundan geçmeden cânân arzû kılursin

62

Aceb degül seniniçün ger cân fedâ kılurısam

Yukarıdaki beyitlerde eşanlamlı/eşgönderimli sözcüklerle (cân olsun / can kurban kılmak / cânundan geçmek) eşdizimlilik oluşturulmuş. Dizimlerde sözcüklerin yer değiştirdiği ve araya başka sözcüklerin girdiği görülmektedir.

\section{Cân / olmak}

cân ve olmak eşdizimliliği sevimli, hoş görünmek anlamlarına gelmektedir. Tasavvufi anlamda bakılınca cân olmak, birbirine kuvvetli muhabbet bağı ile bağlanmaktır. Bu anlamda herkese cân denilmez, cân olan muhabbet yolunda maddi manevi her şeyini feda eder. Âşık olgunlaşmıştır, kendisine hasbî dost arar, bu 
dostluğa cân olmak denir ki ölü gönlü bile diriltir, umman ortasında kalanı balık karnında sahil-i selamete çıkarır, gönül tahtına oturur... Onun uğruna cân feda edilir. Yunus Emre Divanı'nda 8 yerde cân ve olmak sözcükleri eşdizimlilik oluşturmuştur. Bütün beyitlerde açmazların hepsini çözen bir anahtar gibidir cân olmak.

63

Evvel benem âhir benem cânlara cân olan benem

Azup yolda kalanlara hâzır meded iden benem

64

Ol cân kaçan öliser sen ana cân olasin

Ölmiş gönül dirile anda ki sen olasın

65

Eger 'ı̧̧ıı seversen cân olasin

Gönüller tahtına sultân olasın

66

Bende bakdum bende gördüm benümile ben olanı

Sûretüme cân olanı kimdügini bildüm ahî

67

Dâr olam girdâr olam ber-dâr olam Mansûr olam

Cân olam hem ten olam hem în olam hem ân olam

68

Gah batn-ı Hût içinde Yûnus'ila söyleşem

Geh çıkam 'Arş̧üzere bir cân olam Selmân olam

69

İy Yûnus imdi senün 'ş̧kıla geçsün günün

Sevdügün kişi senün cânuna cân olısar

\section{Cân / virmek (Cân vermek)}

KL'de cân vermek "1. Ölmek, s. Sen Fuzûlî yâr yolunda can verirsen âkıbet / İşidenler diyeler "innâ ileyhi râciûn" (Fuzûlî). Gülün gölgesinde can verir bülbül (Ali M. Arolat). 2. (Bir şey uğruna) Canını fedâ etmek, s. Gerçi verir dilbere her kişi can / Ey Necâtî sana dilber can verir (Necâtî Bey - Ş.A.D.). Fethin daha bir ülkeyi parlattığı gündü / Biz uğruna can verdiğimiz yerde göründü (Yahyâ Kemal). 3. Uğruna can fedâ edecek kadar çok istemek, canını vermek, s. Gemi gelir yan verir / İskeleye şan verir / Şu İstanbul kızları / Koca diye can verir (Türkü - Ş.A.D.)” şeklinde açılanmıştır.

İnsan aşk yoluna girince o yolda cân verir. Cân veren pervaneler, ışığa âşık olan pervanelerdir. Her âşık, maşuku uğrunda gönüllü olarak cân verir. "Istırabın zirvesi ve sadakatin en yüce tasdik makamı ise maşuk uğrunda cân vermektir. Bu durum sufi çevrelerde çokça yorumlanan 'ölmeden önce ölünüz' hadisiyle gerekçelendirilmiş, âşığın kendi varlığından geçmesi, nefsinden sıyrılması ve fena makamına ulaşması için şart görülmüştür. Âşık maşuktan gelen her şeye razıdır ve kayıtsız şartsız bir teslimiyet içindedir” (Öztürk, 2014, s. 35). Yunus Emre divanında 22 yerde cân ve vermek sözcükleri eşdizimlilik oluşturmuştur. Son örnekte 'cân vermek'le eşanlamlı ve eşgönderimli dost yoluna îsâr olmak kullanılmış, bu yapı da cân vermek ile eşanlamlı eşdizimlilik oluşturmuştur.

70

Her kim tarîka gire gerek mâl terkin ura

Yola togrı cân vire bu tarîkat içinde 


\section{1}

Ger togrı turmazısa mâl terkin urmazısa Yola cân virmezise tuymaz sohbet içinde 72

'Âşık mıdur ol ma'şûk içün virmeye cânı

'Âkil midür ol dünyeyile isteye anı

73

Kendüligin terkin ura senün yolunda cân vire

Sorısuz uçmaga gire sen sultâna iren kişi

74

Cânını şükrâne vire yüzin ayaklara süre

Erenler gönline gire Hak'dan haber soran kişi

75

İsidün iy yârânlar

Eve dervîşler geldi

Cân şükrâne virelüm

Eve dervîşler geldi

76

Eşkere kıldum bugün pinhânumı

Cân virüben buldum ol cânânumı

77

Ferhâd bu 'ışk yolında başın külünge tutdı

Hüsrev Şîîn derdinden dosta virdi cânını

78

Cânını 'aşk yolına virmeyen 'âşık mıdur 79

N'iderüz dirlik suyın biz cânı yagmaya virdük 80

Diledi göre yüzin işide kendü sözin

Nazar kıldı bir kezin anda cân virdi bana

81

İsidürem sözini göremezem yüzini

Yüzini görmeklige cânum viresüm gelür

82

'Ârif cân virür tuymaz yalancı mâla kıymaz

Yalanila gerçegi berâber tutmayalar

83

Benem zârî kılan şol yâre karşu

Gönülden cân viren dildâre karşu

84

Yûnus miskîn kalmaz câna virür cânını kurbâna Gelsen sıgınsan Sübhân'a togru yola gitsen gönül 85

Dost elinden ölürisem güle güle girü gelem

Ganîmet görem bu demi cân şükrâne virü gelem

86

Dostdan bana haber geldi turayım andan varayım 
Kurbânlıga bu cânumı vireyim andan varayım

87

'Işkdur bu derdün dermânı 'ş̧sk yolına virdüm cânı

Miskîn Yûnus dir yâ Ganî bir dem 'ışksuz kalmayayın

88

Kimdür ki dost yüzin göre dost dost diyü cânın vire

Şolok dem ol dosta ire unıda cümle teşvîşi

89

Girçek âşılk ol ola cân virmege ol ive

Dostıla bâzâr içün niçe bin başdan geçer

90

Kanı girçek 'âşık kanı gelün isteyelim anı

Bî-çâre Yûnus'un cânı dost yolına îsâr olur

\section{Cân kuşu}

KL'de cân kuşu, s. mec. "Can, ruh, s. Can kuşu kafesten âkıbet uçar (Pir Sultan Abdal)." şeklinde açılanmıştır. Cân kuşu Yunus Emre Divanı'nda ruh, ölüm anlamlarına gelmektedir. Cân kuşunun uçup gitmesi, ölmek anlamında kullanılmıştır. Alttaki son beyitte cân kuşu yerine eşanlamlı ve eşgönderimli ömür kuşu kullanılmıştır. Beyitlerin tamamında cân kuşu, insanın faniliğine vurgu yapmaktadır. Malum insan sözcüğü unutmakla alakalıdır, bu noktada Yunus Emre insanoğlunu en zayıf yönü olan gafletten uzak durması hususunda uyarmakta, bunun için de insanın faniliğini bir an için bile unutmaması, gaflete düşmemesi gerektiğini belirtmektedir.

91

Katreden deryâlar düzen cân kuşı pâ-bendin üzen

Yüz bin deryâları yüzen gel sürelüm bu çagları

92

Gider gönül teşvîşüni

Bezeme hoyrat nakşunı

Uçurmadın cân kuşunı

Gel ikrâr it erenlere

93

Benüm cânum bir kuş durur gevdem anun kafesidür

Dostdan haber gelicegiz bir gün uçar kuşum benüm

94

İy benüm ‘ömrüm kuşı kanda varasın birgün

Ecel avlayup yudar ele giresin birgün

\section{Sonuç}

Yunus Emre bir aşk, sevgi ve gönül insanıdır. Bu kavramların insanda tecelli ettiği yerler olarak gösterilen kalp, dil (Far.), hatır/hâtır, gönül, yürek ve cân sözcüklerinin Yunus Emre Divanı'nda hangi sözcük(ler)le eşdizimlilik oluşturduğu incelenmiş, çalışmada 94 yerde eşdizimlilik tespit edilmiş, bunların 73 'ünün yan yana 22 'sinin de aynı beyitte, ancak araya sözcük alarak eşdizimlilik oluşturduğu tespit edilmiştir. Hem araya sözcük alma hem de yer değiştirme şeklinde eşdizimlilikler ise 8 yerde görülmüştür. Aşağıdaki beyitte hem unsurlar yer değiştirmiş (cân almak / alur cânı) hem de araya sözcük girmiştir (alur yine cânı). 


\section{Yûnus kim öldürür seni viren alur yine cânı}

Yarın göresin sen anı er nazarından gitmegil

Yunus Emre Divanı'nda kalp sözcügü 5 yerde, dil ve hatır/hâtır sözcükleri ise 3 yerde geçmiş, ancak bu sözcükler eşdizimlilik oluşturmamıştır. Başka sözcüklerle en çok eşdizim oluşturan sözcük ise 5 eşdizimlilik (cân almak, cân feda etmek, cân olmak, cân vermek ve cân kuşu) ile cân sözcügü olmuştur. Soyut kavramlar olan kalp, dil (Far.), hatır/hâtır, gönül, yürek ve cân'in en fazla eşdizimlilik oluşturduğu yapı ise 48 sözcük ile cân olmuştur. Bu da bize aşk, sevgi ve muhabbetin Yunus'ta en çok cân sözcüğü ile ifade edildiğini göstermektedir. En fazla eşdizimlik örneği ise yine 5 farklı sözcükle (cân almak, cân feda kılmak, cân olmak, cân vermek ve cân kuşu) eşdizimlilik oluşturan cân sözcügü olmuştur.

Konuşma dili ve diğer yazılı metinlerde oldukça yaygın kullanıma sahip olan eşdizimli bir yapı, Yunus Emre Divanı'ında şayet en ez üç yerde eşdizimlilik oluşturuyorsa eşdizimli kabul edilmiştir. Çalışmada ilginç verilerden birisi de aslında ikişer kez geçen, ancak birbiri ile eşanlamlı ve eşgönderimli şekilde bakılınca toplamda altı kez geçen gönül şehri eşdizimli kabul edilmiştir. Birbiri ile açıkça eşanlamlı ve oldukça yakın duygu değeri taşıyan gönül evi (2), gönül şehri (2), dil şehri (1) ve cân şehri (1) şeklindeki yapılar eşdizimli kabul edilmiştir.

Bulgularda ad+ad yapısında (gönül/göz, gönül/şehir, yürek aşk, yürek/aşk odu, yürek/aşk oku, cân kuşu) 6 eşdizimlilik, ad+eylem yapısında ise (yürek/yanmak, cân almak, cân feda kılmak, cân olmak, cân vermek) 5 eşdizimlilik elde edilmiştir.

Çalışmada incelenen sözcükler birbirlerine oldukça yakın anlam değeri taşımalarına rağmen, farklı sözcüklerle eşdizimlilik oluşturdukları, bu farklı yapıların da söylem ezgisi açısından oldukça farklı duygu değerlerine sahip olduğu görülmüştür. Bu nedenle yakın anlamlı olarak değerlendirebileceğimiz sevgi, muhabbet gibi kavramlar etrafında oluşmuş bu sözcüklerin (kalp, dil (Far.), hatır/hâtır, gönül, yürek ve cân), yakın gönderimli sözcükler olsalar da farklı nüansları ifade eden eşdizimlilikler olduğu görülmektedir. Aradaki bu ince anlam farkları büyük çoğunlukla farklı sözcüklerle kurulan eşdizimliliklerle ifade edildiği, bunların her birisinin de farklı duygu değerine sahip olduğu, birbirinin yerine ikame edilemediği görülmektedir. Örneğin aşk uğrunda fedakârlıkta bulunulacaksa seve seve "Âşık mıdur ol ma'ş̂̂k içün virmeye cânı" dizesinde olduğu gibi cân vermek eşdizimliliği kullanılmakta, cân yerine kalp, gönüll veya yürek feda etmek kullanılmamaktadır. Türkçede günlük dilde kalp kırmak ve gönül kırmak eşdizimlilikleri birbirine oldukça yakın duygu değerine sahiptir. Ancak Yunus Emre divanında ele aldığımız altı sözcüğün hiçbirisinin (kalp, dil (Far.), hatır/hâtır, gönül, yürek ve cân) bir diğerinin yerine kullanılmamış olduğunu görmekteyiz. Bu da bize dilde nedensiz olarak gösterilen eşdizimliliklerin büyük bir çoğunlukla farklı duygu değerine sahip oldukları, aynı deneyimleri yaşayan insanların ortak duyguları ifade etmek üzere uzlaşı halinde kavramsallatırdıkları, bu yapıların toplumsal bir ihtiyaca karşılık geldiği, herkesçe aynı duyguyu ifade etmek üzere kullanıldığı anlaşılmaktadır. Çalışmada ele alınan sözcükler, duygu değeri ve ifade ettikleri anlam bakımından incelenince milletlerin dahil oldukları medeniyet dairesini de gösterdiğini söyleyebiliriz. Bu yapıların Batı dillerinde tam karşılığı yoktur, tasavvuf kültürü çerçevesinde yüzyıllar önce teşekkül eden bu eşdizimli kavramlar, yüzyıllar içinde toplumun tamamına mâl olmuş, günümüzde de günlük dilimizde kullanılmaktadır.

Yunus Emre Divanı'ndan elde edilen gönül ve yürek sözcükleri ile ilgili eşdizimli yapılar duygu yoğunluğu açısından ortalama bir duygu değerine sahipken, cân sözcügünün ise ortalama duygu değerinin üzerinde olduğu (cân vermek, cân almak, cân feda etmek vb.) görülmektedir. Cân sözcüğündeki bu duygu yoğunluğu ortalamının çok çok üzerinde duyguları ifade etmede, daha fazla fedakârlık ve feragat ifade etmekte oldukça kullanışlı eşdizimli yapılar oluşturmuştur. Gönül sözcüğüne göre yürek ve kalp biribirine daha yakın, çünkü 
daha çok kalbin maddi yönünü ifade ettikleri görülmekte, gönül de adeta bu iki sözcügün orta noktasında daha çok bu kavramların manevi yönlerini ifade etmektedir. Günlük dilde kabaca eşanlamlı olarak nitelendirilen sözcüklerin gönderimleri yakın duygu değerine sahip olsa da aynı duygu değerine sahip olmadıkları için tam olarak eşgönderimde bulunmaları oldukça zordur. Bu nedenle eşanlamlı sözcüklerle oluşturulan eşdizimli yapıların aslında tam anlamıyla eşanlamlı olmadıkları, yakın anlamlı oldukları görülmektedir. "yakınanlamlılık ilişkisindeki sözcüklerin doğruluk koşulları ve önermeyi etkilediğini, bu bağlamda birbirinin yerine kullanılma olasılığı her zaman olmadığını belirtir. Bu açıdan alanyazında 'eşanlamlı' olarak adlandırılan yapıların büyük çoğunluğunun aslında yakınanlamlılık ilişkisi kurduğu söylenebilir.” (Gündoğdu, 2019, s. 457).

Metinden elde edilen eşdizimli yapıların bir kısmı ikili (iki sözcük) bir kısmı da üçlü (üç sözcük) yapılardır. Metinden elde edilen 77 ikili eşdizimlilikten yalnızca 4'ü araya başka sözcük almış, bu da toplam ikili eşdizimliliğin \% 5’inin araya farklı sözcük aldığını göstermektedir. Yine metinden elde edilen 18 üçlü eşdizimlilikten 8'inin araya başka sözcük aldığı, bu da üçlü eşdizimliliklerin \% 44’ünün araya farklı sözcük aldığını göstermektedir. Bu da bize ikili eşdizimliliklerin üçlü dizimliliklere göre daha fazla araya farklı sözcük aldığını göstermektedir.

\section{Kaynakça}

Akbalık E. (2013). Yunus emre’nin şiirlerinde 'gönül' imgesi, Uluslararası Sosyal Araştırmalar Dergisi, 6(26), 20-28. Erişim adresi: http://turkoloji.cu.edu.tr/pdf/esra_akbalik_yunus_emre_gonul.pdf

Eken, N. T. (2016). Eşdizimlerin saptanmasına ve betimlenmesine yönelik kuram ve aklaşımlar. Mustafa Kemal Üniversitesi Sosyal Bilimler Enstitüsü Dergisi, 13, 28-47. Erişim adresi: https://dergipark.org.tr/tr/pub/mkusbed/issue/19579/209020

Gündoğdu, A. E. (2019). Eşdizimlilik görünümleri dilde bilişsel yapılanmaya ilişkin ne söyler? Türkçede 'aşk, sevgi, sevda’ sözcüklerinin derlem temelli incelenmesi. Söylem Filoloji Dergisi, 4, 455-469. Erişim adresi: https://dergipark.org.tr/en/download/article-file/911123

İmer, K., Kocaman, A. ve Özsoy, S. (2011). Dilbilim sözlü̆̆̈̈, İstanbul: Boğaziçi Üniversitesi Yayınevi.

Kurnaz, C. (1996). Gönül. TDV İslâm Ansiklopedisi, (14), 150-152. Erişim adresi: https://islamansiklopedisi.org.tr/gonul -turk-edebiyati.

Okudan, R. (2012). Hacı bayram veli'nin şiirlerinde şehir metaforu. Süleyman Demirel Üniversitesi Sosyal Bilimler Dergisi, 2(16), 265-278. Erişim adresi: https://dergipark.org.tr/tr/download/article-file/215328

Onat Çakıroğlu, T. (2013). Yunus Emre divanı’nda gönül. Giresun Üniversitesi Sosyal Bilimler Enstitüsü Karadeniz Sosyal Bilimler Dergisi, 9, 77-87. Erişim adresi: https://dergipark.org.tr/tr/download/articlefile/149878

Özkan, B. (2012). Türkiye Türkçesinin eşdizim sözlügü, M. N. Önal (Ed.) IV. Uluslararası Dünya Dili Türkçe Sempozyumu bildirileri. II. (s. 93-102), Ankara. Erişim adresi: http://turkoloji.cu.edu.tr/pdf/bulent_ozkan_esdizim_sozlugu.pdf

Öztürk, M. (2014). Klasik Türk edebiyatında can verme arzusu ve intihar. Mustafa Kemal Üniversitesi Sosyal Bilimler Enstitüsü Dergisi, 11(27), 33-51. Erişim adresi: https://dergipark.org.tr/tr/download/articlefile/183356

Tatçı, M. (1990). Yunus Emre Divanı- İnceleme, Ankara: Kültür Bakanlığı Yayınları. 
Sert, G. (2019). Anlam alanı ve anlam ezgisi açısından eş anlamlı durum sıfatları: “muhtemel” ve "olası" örneği. Uluslararası Türkçe Edebiyat Kültür Eğitim Dergisi, 8, 93-121. Erişim adresi: https://dergipark.org.tr/tr/download/article-file/685494

Uludağ, S. (1992). Basîret, TDV İslâm Ansiklopedisi, (5), $103 . \quad$ Erişim adresi: https://islamansiklopedisi.org.tr/basiret-turk-edebiyati.

Uzun, M. İ. (1993). Can. TDV İslâm Ansiklopedisi, (7), 138-139. Erişim adresi: https://islamansiklopedisi.org.tr/can-turk-edebiyati.

Vardar, B. (2002). Açıklamalı Dilbilim Terimleri Sözlüğü, İstanbul: Multilingual Yayınları.

\section{Extended Abstract}

\section{Purpose}

Yunus Emre is a person of love, compassion and compassion. The study is limited to Yunus Emre's Divan only. The collocations of the words heart, dil (Far.), sake / sake, feeling, heart and soul, which are seen as the places where these feelings manifest in humans, are emphasized. Although these words have similar meanings in Turkish, each has different systematic uses and references. In the study, attention was paid to create collocation or synonymous structures at least 3 times in the divan in order for the words to be collocation, and the collocations that are widely used in daily language even today will not be considered collocations unless there are at least three. usage examples.

\section{Design and Methodology}

In the research, a literature review was made and document analysis was performed as a data collection method. The findings obtained from the research were analyzed using content analysis. Collocation is generally defined as "The presence of two or more units in the same sequence" (İmer et al. 2011, p. 121; Vardar, 2002, pp. 94-95). Collocations are generally considered from two different perspectives, the statistics-based approach and the meaning-based approach. Statistics-based approach accepts words obtained from the corpus according to a certain criterion and used side by side only as collocations, while semantic-based approach accepts words in this situation as collocation if they have the same semantic value in the context.

This study is limited to Yunus Emre's Divan, however, collocational words (heart, tongue (Far.), sake, heart, heart and soul) examined in this study are not unique to Yunus Emre. "The said uses include not only individual language uses, but also general uses of language with a holistic distribution. Parallel to this feature, it is possible to say that collocations show causelessness in many cases."(Gündoğdu, 2019, p. 457).

In the study, in some cases, it was observed that the words forming collocations changed places without changing their meaning value (heart and eye / eye and heart):

Yûnus imdi sen Hakk'a ir dün ü gün gönlün Hakk'a vir

Gönül gözi görmeyince bu baş gözi görmeyiser

Eyâ gâfil aç gözüni gönlün yavlak uzatmagıl

Bakgll kendü dirligüne kimse 'aybın gözetmegil

Every word discussed in the study is explained with quotations from the Current Turkish Dictionary (Current Turkish Dictionary) and Kubbealtı Lugatı (KB). Afterwards, information was given about how these words found a response in literature and Yunus Emre's Divan, and the message given with these words was emphasized. In the collocation sub-headings, if there is an explanation in the $\mathrm{KB}$ about the relevant structure, they are also given. 


\section{Findings / Bulgular}

\section{Gönül}

The word heart represents the spiritual aspect of the heart. It is seen that the word heart is predominantly preferred, even if the word heart expresses this meaning with close reference. In Sufism, the heart represents the merciful side of the human heart, while the nafs represents the lowly side.

The structures in which the word heart is collocation in the Divan are as follows:

\section{Gönül / göz (gönül gözü)}

The eye of the heart is one of the mystical concepts he uses most. It is the gift of intuition found in mature believers. It is to look at the world in terms of meaning rather than with material eyes.

Yûnus imdi sen Hakk'a ir dün ü gün gönlün Hakk'a vir

Gönül gözi görmeyince bu baş gözi görmeyiser

\section{Yürek}

Turkish heart, which is synonymous with the Arabic heart, is seen as a place where merciful feelings dominate. The word "heart" is the voice of conscience in our hearts, listening to the voice of the heart means being conscientious.

\section{Yürek / 'ışk odu}

As long as the fire of love burns, love continues, so even though it hurts the heart, it is not desired that the fire of love goes out.

İy dost senün 'ş̧kun odı cigerüm pâre baş kılur

'Işkundan yanar yüregüm yandugum bana hoş gelür

\section{Cân}

The word can has many different meanings in dictionaries. In literature, it is sacrificing one's life in order to achieve desires with high spiritual value. Since the soul is intangible, it is considered volatile, and in this respect it has also been compared to birds. Words that form collocations with jan are:

\section{Cân / almak}

The words can and take are related to life and vitality. It is God who gives life to man, and it is God who will take it. Man is mortal, God is eternal, therefore, the owner of a mortal soul knows that the one who gives it to him will take it one day.

Nazarun bin cân alur derdün yürekde kalur

Gören kendüden varur 'âşıka kıyan mısın

\section{Research Limitations}

Yunus Emre is a person of love, affection and affection. The study is limited to Yunus Emre's Divan only. The collocations of the words heart, tongue (Far.), sake/hatır, heart, heart and soul, which are seen as the places where these feelings are manifested in people, are emphasized.

\section{Implications}

In the research, the collocations of 5 words used in Sufism in Yunus Emre's Divan were emphasized. Due to the limitations of this study, the Turkish equivalents of mystical concepts in Yunus Emre could not be discussed. With the studies to be done, it will be possible to determine what kind of collocations these concepts form in Turkish. 
In Yunus Emre's Divan, it was examined which word(s) the words heart, tongue (Far.), sake/hatır, heart, heart and soul form collocations, collocations were determined in 95 places, 73 of them side by side and 22 of them have the same collocation. It has been determined that the couplet creates collocations only by adding words together. Of these, 13 are collocations in the form of displacement. Collocations in the form of both word insertion and substitution were observed in 8 places. In the couplet below, both the elements have changed places (can alma / alur cani) and the word has been inserted (alur again cani).

\section{Yûnus kim öldürür seni viren alur yine cânı}

Yarın göresin sen anı er nazarından gitmegil

In Yunus Emre's Divan, the word heart is used in 5 places, and the words tongue and sake / sake are used in 3 places, but these words do not form collocations. The word that formed the most collocations with other words was the word can, with 5 collocations (taking life, sacrificing life, being alive, giving life and bird of life). The structure in which the abstract concepts heart, tongue (Far.), sake/remember, heart, heart and soul formed the most collocations was can with 48 words. This shows us that love, affection and conversation are mostly expressed with the word soul in Yunus. The highest number of collocation examples is the word can, which creates collocation with 5 different words (taking life, sacrificing life, being alive, giving life and bird of life). In the findings, there are 6 collocations in the name+name structure (heart/eye, heart/city, heart love, heart/love arrow, heart/love arrow, soul bird) and in the name+action structure (heart/burn, taking life, sacrificing life, 5 collocations were obtained.

Although the words examined in the study have very close meaning values to each other, it has been seen that they form collocations with different words, and these different structures have quite different emotional values in terms of discourse melody. For this reason, it is seen that these words (heart, tongue (Far.), sake/remember, heart, heart and soul), which are formed around concepts such as love and conversation, which we can evaluate as closely related, are collocations expressing different nuances, even though they are words with close references. However, we see that none of the six words (heart, tongue (Far.), sake/remember, heart, heart and soul) we discussed in Yunus Emre's divan were used in place of each other.

While the collocational structures about the words heart and heart obtained from Yunus Emre's Divan have an average emotional value in terms of emotional intensity, it is seen that the word can is above the average emotional value (giving life, taking life, sacrificing one's life, etc.). This intensity of emotion in the word can has created collocational structures that are very useful in expressing emotions far above the average and expressing more sacrifice and renunciation.

Some of the collocation structures obtained from the text are binary (two words) and some are triple (three words) structures. Only 4 out of 77 binary collocations obtained from the text included other words, indicating that $5 \%$ of the total binary collocations included different words. Again, 8 out of 18 triple collocations obtained from the text included other words, which shows that $44 \%$ of triple collocations included different words. This shows us that double collocations take different words together more than triple collocations.

\section{Originality/Value}

There has been no previous research on the words heart, tongue (Far.), sake / sake, feeling, heart and soul, which are discussed in the research, with which words they are collocations, meaning melodies and whether they are used interchangeably.

Araştırmacı Katkısı: Bilal UYSAL (\%100). 